\title{
FRAMING CATASTROPHIC FAILURE AS A LEARNING OPPORTUNITY
}

\author{
SEN CHAI \\ ESSEC Business School, 3 Avenue Bernard Hirsch, Cergy-Pontoise, France
}

ANIL R. DOSHI

UCL School of Management

LUCIANA SILVESTRI

Harvard Business School

\section{INTRODUCTION}

Scholars (e.g., Edmondson, 2011; Sitkin, 1992) and practitioners (e.g., Kelley \& Littman, 2001) have hailed failure as a valuable and critical instance in the production of radical innovations. They posit that failure acts as a powerful trigger of organizational learning (Khanna, Guler \& Nerkar, 2015; Maslach, 2016) toward the development of new-to-the-world products, processes, and technologies. In their view, failure can facilitate learning by shedding light on faulty assumptions, illuminating unexplored lines of enquiry, and giving rise to new, untested hypotheses (McGrath, 2011). This attitude toward failure is especially critical for firms in nascent industries, whose survival ultimately depends on bringing radical innovations to market in an efficient and timely manner. When failure happens, these firms are faced with the challenge of framing the failure in favorable ways in order to sustain stakeholder support.

Stakeholder support is critical for firms in the aftermath of failure. Failure may lead stakeholders to change their attitude toward the firm by demanding more accountability, reducing their appetite for experimentation, or intervening and calling for a change in direction (Freeman, 2010). Stakeholders may also threaten to withdraw valuable resources or present the firm with a more stringent set of conditions to provide resources in the future. Responses such as these may derail the organization's innovation process, which needs slack to allow for failure (Manso, 2011), and ultimately endanger the firm's survival.

Stakeholder support is especially crucial for firms in nascent industries that experience catastrophic failure, i.e., an extreme form of failure that occurs suddenly and unexpectedly, and which causes widespread loss of valuable tangible and intangible assets. Catastrophic failure tends to occur on rare occasions but, when it does, it proves highly salient for both the firm and its stakeholders (Lampel, Shamsie, \& Shapira, 2009; Harding, Fox, \& Mehta. 2002).

Catastrophic failure is especially likely to raise doubts about the firm's ability to execute, and would more quickly bring to bear the external pressures from stakeholders discussed above. While catastrophic failure offers the firm important lessons if analyzed "richly" (March, Sproull, \& Tamuz, 1991; Beck \& Plowman, 2009), those lessons can only be learned if the firm is able to frame the failure in terms that will induce stakeholders to maintain their support.

Our goal in this paper is to examine how firms in nascent industries frame catastrophic failure vis-à-vis their stakeholders (Goffman, 1974). We seek to identify the sensegiving mechanisms firms in nascent industries use to influence stakeholders' understanding of the failure and communicate a preferred interpretation of the event (Gioia and Chittipeddi, 1999). Since catastrophic failure can involve the loss of technology or the loss of technology and human 
lives, we are also interested in ascertaining whether there is variance in the way firms use these sensegiving mechanisms when faced with catastrophic failure of different severity.

Through an inductive qualitative study, we contrast two instances of catastrophic failure in the commercial space transportation industry. On the one hand, we look at the October 2014 crash of Virgin Galactic's SpaceShipTwo vehicle, which caused the total loss of the technology, the death of the pilot, and severe injuries to another. On the other, we examine the crash experienced by SpaceX's vehicle in June 2015 during a commercial resupply mission to the International Space Station, where technology was completely lost but no lives were at stake. Our analysis relies on a rich archival dataset, which includes tweets, press releases, website content, and executive blog entries produced by these firms to publicly frame their respective failures. The nature of our dataset allowed us to rely on real-time accounts of the events, thereby minimizing the risk of retrospective bias.

Our paper answers recent calls to examine the relationship between learning, firm legitimacy in the eyes of stakeholders, and the narratives firms craft in the aftermath of rare events (Lampel, Shamsie, \& Shapira, 2009). Our findings inform the entrepreneurship literature by shedding light on sensegiving, framing, and storytelling processes in the aftermath of catastrophic failure (Navis \& Glynn, 2010; Garud, Schildt, \& Lant, 2015). We also contribute to the literature on failure in innovation by explicitly looking at catastrophic failures of different degrees of severity. Catastrophic failures have been historically examined in the context of natural disasters or organization-level processes involving involves negligence or bad faith (Oetzl and Oh, 2014; Gillepsie and Dietz, 2009). We offer an analysis of catastrophic failure that occurs despite firms' best efforts, with tragic consequences.

\section{METHODS}

In order to explore how firms in nascent industries frame catastrophic failure, we performed an inductive qualitative study. Inductive qualitative methods allow the researcher to understand events from the perspective of its protagonists and to "make sense of, or interpret, phenomena in terms of the meanings people bring to them" (Denzin and Lincoln 2008:4). Our goal here is to build and elaborate, rather than test, theory (Edmondson and McManus, 2007). Given the paucity of examples of highly salient catastrophic failure, we relied on theoretical sampling (Glaser and Strauss, 1967) and opted for two unusually revelatory cases (Eisenhardt, 1989; Siggelkow, 2007; Pratt, 2009): the Virgin Galactic ("VG") 2014 test flight crash and the SpaceX ("SX") June 2015 crash during the Commercial Resupply Services 7 mission (CRS-7).

VG was founded in 2004, when Sir Richard Branson, founder of the Virgin Group, licensed the technology behind SpaceShipOne, an experimental vehicle that would be able to take passengers into suborbital space. VG planned to allow passengers to experience weightlessness for about 15 minutes and to see the Earth from a vantage point usually reserved to career astronauts. Tickets went on sale for 200,000 USD; the price was later increased to 250,000 USD. On October 31, 2014, during a test flight, VG's new spacecraft SpaceShipTwo broke apart in mid-air shortly after being released by its carrier WhiteKnightTwo. The accident killed pilot Michael Alsbury and seriously injured co-pilot Peter Siebold. By the time the test flight crash occurred, more than 700 people had signed up and awaited VG's maiden voyage.

SX was founded in 2002 by entrepreneur Elon Musk with the goal of revolutionizing access to space by reducing the cost of space transportation, and enabling the colonization of Mars. While its missions have so far been unmanned, SX designed its Dragon spacecraft for 
eventual manned missions from the onset. Unlike prior rocket technology where the propulsion stages would be dropped and lost upon launch, SX has also developed the multi-use Falcon 9 launch vehicle that can be recovered after launch and reused, improving the affordability of space transportation. At the time of the crash, Dragon was being tested in unmanned missions to replenish the International Space Station. Although starting 2014 various initial attempts in the recovery of Falcon 9 led to failed landings, SX's most severe failure occurred on June 28, 2015 when the Falcon 9 exploded during ascent, resulting in the complete and catastrophic loss of the launch vehicle and the Dragon spacecraft.

\section{Data collection}

We compare the catastrophic failure experienced by VG to the most severe failure experienced by SX. For VG, we took the October 31, 2014 test flight crash as the focal event and collected data for a period spanning six months (three months pre- and post-event). Similarly, for SX we took the June 28, 2015 Falcon 9 mid-flight explosion as the focal event and collected data for 6 months (three months pre- and post-event). Our primary data came from diverse archival sources in traditional and social media.

\section{Social Media and Blogs}

We gathered all tweets posted during our data collection period in VG's and SX's corporate accounts (@virgingalactic and@spacex), as well as in the accounts of top executives. We complemented these data with VG-related tweets published in founder Sir Richard Branson's personal account (@richardbranson) and SX-related tweets published by founder Elon Musk (@elonmusk). This yielded a total of over 1,500 tweets. We also collected blog entries for each company's founder. Both leaders keep active blogs. Their personal annotations about their companies tend to be insightful, and are widely followed.

\section{Corporate Websites and Press Releases}

We noticed that tweets and blog entries often included links to other corporate sources. This prompted us to collect content published by VG and SX on these outlets. Using Archive.org's Wayback Machine, a tool which provides archival access to websites, we gathered all content visible on VG and SX's corporate website (www.virgingalactic.com and www.spacex.com) during our data collection period. This enabled us to assess changes in the firms' narratives both before and in the aftermath of each crash.

We also gathered all press releases produced by each firm during our data collection period. Press releases constitute formal messages produced by a firm directed at media outlets. Since they often include direct quotes from top managers, press releases provide rich real-time rich data on issues the firm considers newsworthy.

\section{Data analysis}

Our goal in data analysis was to understand and contrast how VG and SX framed the catastrophic failures they experienced. We started by familiarizing ourselves with VG and SX's respective histories and built timelines of key milestones. We began our analysis of the data itself 
by focusing on the firm's tweets. We chose to start here because tweets are, possibly, the most straightforward and candid messages an organization can direct at its stakeholders. The first and third authors each focused on one company. We divided the data by month, noting the number of tweets published in each period. We then engaged in open coding separately, looking for emergent themes (Strauss and Corbin, 1990). Given that tweets have a maximum length of 140 characters, the vast majority of them revolved around a single theme. As themes emerged, we generated in-vivo codes. We then came together, contrasted our emergent codes, and generated a common scheme that included higher- and lower-level categories (Strauss and Corbin, 1990).

We then used this coding scheme to examine the rest of our data sources. We started with the companies' websites and founders' blog posts. We saw that website and blog content often expanded on the themes stated in the tweets, and this gave us a chance to enrich our coding scheme. Lastly, we coded each company's press releases. Combining insights from all of our data sources, we induced a variance model of framing catastrophic failure in nascent industries. As is typical in inductive research, we iterated frequently between data analysis (looking at emergent insights within and across our two cases), theory development, and review of the literature (Locke, 2001). Our analysis ended when we felt we had reached theoretical saturation.

\section{RESULTS}

Our analysis shows that the nature of a catastrophic event determines how firms frame catastrophic failure. The sensegiving mechanisms firms use in the face of catastrophic failure vary drastically when there is and isn't loss of human life. We found that VG radically altered the narrative of its organizational identity in the aftermath of its test flight crash, and framed the failure in ways that reinforced this renewed identity narrative. In contrast, SX demonstrated no such behavior: its identity narrative and understanding of the meaning of failure changed little after the catastrophic loss of its launch vehicle and spacecraft.

Before its 2014 crash, VG defined itself as "the first commercial spaceline". There was a tight link between this identity and external, tangible aspects of the firm's operations. First and foremost, the firm connected its identity to the technology it was developing. On a press sheet, VG declared its vision was to "produce a new space reusable space system which aims to transform access to outer space." The firm's reusable spacecraft would "provide affordable and safe launch opportunities for astronauts and research payloads" and "increase the frequency of space flight" thanks to their "innovative design" and "low prices". On its website, VG also highlighted the construction of its spaceport, noting it had been designed by famed architectural firm Foster + Partners. VG stated that "the sinuous shape of the building ... and its interior spaces seek to capture the drama and mystery of space flight itself," constituting "the first facility of its kind and a model for the future". Lastly, the firm appeared to craft one-to-one relationships with its customers. Narratives centered on the individual experience of flying on VG's vehicle. On the website, VG noted: "As you hurtle through the edges of the atmosphere, the large windows show the cobalt blue sky turning to mauve and indigo and finally to black. You're on a high; this is really happening, you're loving it and you're coping well." The firm stated that becoming a customer meant joining "one of the most exclusive clubs in the world."

There was little reference to failure in VG's narrative pre-crash. Communication across media platforms stressed that the maiden voyage was close to happening. The crash shook the organization to the core. In its aftermath, the firm provided stakeholders with factual data, but the overwhelming majority of its sensegiving process revolved around communicating a newfound 
sense of organizational identity. VG still identified itself as "the first commercial spaceline", but its narrative changed considerably. The firm detached its identity from visible or extrinsic attributes and now highlighted immaterial and intrinsic ones. It completely redesigned the website, including new identity-related sections entitled "who we are" and "why we fly".

There were multiple mentions of "family" that linked VG to its members, on the one hand, and tied VG to its customers and the larger space community, on the other. A section of the website read: "Virgin Galactic is comprised of hundreds of dedicated and passionate professionals ... united in creating something new and lasting: the world's first commercial spaceline." Another identified customers as "future astronauts" and noted: "Our Future Astronauts are an extraordinary group of more than 700 individuals, and they have formed a wonderful community as we have embarked upon the journey towards commercial space flight together." Becoming a customer now meant being "among the first humans ever to fly into space" who would "shape a pioneering program with a lasting legacy, one that will truly open the space frontier." In connection to its inclusion in the wider space community, VG made numerous references to the dream of exploring space to benefit mankind. In a press release, the firm said: "From research, to travel, to innovation, we believe that the technology our industry is pioneering is crucial to the advancement of humanity." A top executive noted that from space "you don't see state and country borders, you see the Earth resources as fragile environments ... In our quest to make space travel available to all ...we hope to lead the charge in teaching the wider population that Earth is something that needs to be better protected."

According to the firm, the benefits that humanity may receive from exploring space made it necessary to endure failure when it occurred. In this way, the firm framed failure as an inescapable cost of innovation. Branson remarked that "Failure is simply indispensable to the entrepreneurial experience" and reportedly told VG employees that "humanity's greatest achievements often come out of our greatest pain." VG also framed the failure as a learning opportunity by saying in a press release: "We are committed to learning from this incident and ensuring something like this can never happen again ... We are all determined to understand the cause of the accident and to learn all we can." Given this framing, VG affirmed its commitment to continue operating. Branson tweeted "Space is hard - but worth it. We will persevere and move forward together" while a press release vowed "we are moving forward and will do so deliberately and with determination." In its post-crash communication, the firm avoided using the word "crash" and instead opted for "anomaly," "accident," and "setback".

Perhaps because VG rarely spoke of failure before the crash, the firm acted somewhat defensively as it crafted its post-crash narrative. Contradicting reports that its customer base would dwindle, the firm stressed the fact that few customers had asked for refunds, while more had made inquiries or signed up. Branson tweeted and blogged about a customer who tattooed the VG logo on his arm as a sign of allegiance to the firm. He also chastised news outlets that rushed to name the causes of the crash, calling it "irresponsible speculation". As VG attempted to install its own interpretation of the failure, he wrote: "When this story is told in years to come, I believe alongside the bravery of Mike and the incredible tale of Pete's survival, will stand the story of the commitment, loyalty and passion of the world's first private astronauts ... Virgin Galactic goes on, with an unwavering commitment to safety and a renewed sense of purpose."

In contrast, SX's narrative did not change much in the aftermath of its catastrophic loss of equipment. Both before and after the crash, SX always saw itself as the first and "only private company ever to return a spacecraft from low-Earth orbit." The firm presented itself as "poised to revolutionize access to space" by "transforming the way rockets are made" and cutting costs. 
On its website and press releases, significant attention and space was dedicated to showcasing the technology. SX's organizational identity was embodied in its technology. The firm took great pride in emphasizing that it designed and manufactured its own rocket and spacecraft in the US: "All of Falcon 9's structures, engines, separation systems, ground systems, and most avionics were designed, manufactured, and tested in the United States by SpaceX ... SpaceX developed Dragon from a blank sheet to its first mission in just over four years." The firm further stressed the link between identity and technology by highlighting the reusability of its launch vehicle. The website explained: "While most rockets are designed to burn up on reentry, SpaceX rockets are designed not only to withstand reentry, but also to return to the launch pad or ocean landing site for a vertical landing."

Before the crash, SX spoke often of the difficulties and challenges of space travel. Musk consistently tweeted preemptive messages prior to launches, such as "Rocket reentry will be much tougher this time around due to deep space mission. Almost $2 X$ force and $4 X$ heat. Plenty of hydraulic fluid tho." In another instance, he wrote: "Odds of rocket landing successfully today are still less than 50\%. The 80\% figure by end of year is only bcs many launches ahead". SX thereby demonstrated that it was comfortable with potential failures. Moreover, failure was framed as a learning opportunity prior to the crash. Similarly, on press kits prior to mission launches, SX systematically included statements such as: "All spaceflight is incredibly complicated. Every component of the mission must operate optimally. Hardware, avionics, sensors, software and communications must function together flawlessly. If any aspect of the mission is not successful, SpaceX will learn from the experience and try again."

After the crash, this straightforward approach to failure was evident in SX's sensegiving process. A press release stated: "While the CRS-7 loss is regrettable, this review process invariably will, in the end, yield a safer and more reliable launch vehicle for all of our customers, including NASA, the United States Air Force, and commercial purchasers of launch services. Critically, the vehicle will be even safer as we begin to carry U.S. astronauts to the International Space Station in 2017. " The firm used mainly factual language to explain the cause of the crash. A press release read: "Preliminary analysis suggests the overpressure event in the upper stage liquid oxygen tank was initiated by a flawed piece of support hardware (a "strut") inside the second stage." No attempts were made to re-narrate SX's organizational identity-it continued to be tied to the technology and to its goal of revolutionizing access to space. Website content remained mostly unaltered: the same press release explaining the cause of the crash stayed on SX's home page for almost 6 months until the next mission, further illustrating the firm's ease with failure.

Like VG, however, SX never referred to the failure as a "crash", and instead used terms such as "mishap" and "problem". A press release read: "Following a nominal liftoff, Falcon 9 experienced a problem shortly before first stage shutdown, resulting in loss of mission... The flight data is our best resource for determining the root cause of Sunday's mishap."

Thus, although both VG and SX are both pioneers in private and commercial space transportation, the difference in the nature of the catastrophic failure they faced - complete loss of technology with or without the loss of human life-led to significantly different reactions in how the firms framed the failure.

\section{REFERENCES AVAILABLE FROM THE AUTHORS}

